\title{
Article
}

\section{Using a Module-based Laboratory To Incorporate Inquiry into a Large Cell Biology Course}

\section{David R. Howard and Jennifer A. Miskowski}

\author{
Department of Biology, University of Wisconsin-La Crosse, 1725 State Street, La Crosse, WI 54601
}

Received September 28, 2004; Revised January 28, 2005; Accepted April 9, 2005

Monitoring Editor: Jeffrey Hardin

\begin{abstract}
Because cell biology has rapidly increased in breadth and depth, instructors are challenged not only to provide undergraduate science students with a strong, up-to-date foundation of knowledge, but also to engage them in the scientific process. To these ends, revision of the Cell Biology Lab course at the University of Wisconsin-La Crosse was undertaken to allow student involvement in experimental design, emphasize data collection and analysis, make connections to the "big picture," and increase student interest in the field. Multiweek laboratory modules were developed as a method to establish an inquiry-based learning environment. Each module utilizes relevant techniques to investigate one or more questions within the context of a fictional story, and there is a progression during the semester from more instructor-guided to more open-ended student investigation. An assessment tool was developed to evaluate student attitudes regarding their lab experience. Analysis of five semesters of data strongly supports the module format as a successful model for inquiry education by increasing student interest and improving attitude toward learning. In addition, student performance on inquiry-based assignments improved over the course of each semester, suggesting an improvement in inquiry-related skills.
\end{abstract}

Keywords: inquiry, undergraduate, laboratory, cell biology, multiweek

\section{INTRODUCTION AND STATEMENT OF PROBLEM}

Cell biology educators are challenged by the continued increase in the amount of information and changes in content as models are revised and new theories emerge. The field of cell biology has experienced an explosion of information in recent years, which has not only greatly increased the depth of understanding of cellular processes, but also expanded the number of topics students face. Cell biology research is increasingly interdisciplinary, often requiring proficiency in a range of traditional disciplines such as genetics, microscopy, molecular biology, biochemistry, evolutionary biology, mathematics, and computer science, and emerging fields such as biophysics and bioinformatics. Our aim was to provide students with a solid background in cell biology and to equip them with the skills they need to synthesize and critically analyze new information. We sought to excite students about the fast-paced and interdisciplinary nature of cell biology

DOI: 10.1187/cbe.04-09-0052

Address correspondence to: Jennifer A. Miskowski (miskowsk. jenn@uwlax.edu). research and to give them a sense of how science is performed instead of simply telling them what is currently known. One major effort to accomplish this goal was the complete revision of the laboratory portion of the Cell Biology course.

The Cell Biology course at the University of Wisconsin-La Crosse (UW-L) is a junior/senior-level course required for all biology majors, which has up to 160 students per year. It consists of $3 \mathrm{~h}$ of lecture and $3 \mathrm{~h}$ of laboratory each week. When we inherited the course 6 yr ago, the laboratory was a series of single-week, standard labs that emphasized metabolic principles using out-of-date equipment. Students methodically followed the protocols to achieve a right or wrong answer at the end of the period. Some students found this inaccurate portrayal of science boring and intimidating, whereas others found it unwelcoming (National Science Foundation, 1996). In addition, student ownership and engagement were low in these replication labs because students were not involved in the design or interpretation of the experiments. Because students are given minimal power in this type of scenario, they are encouraged to use the instructor as a crutch instead of tapping their own skills, strengths, and knowledge base (Brown, 1992; Middlecamp 
and Subramaniam, 1999). We sought to overhaul the laboratory, keeping in mind that any course renovation had to work within the confines of obstacles such as large class size, modest budget, and the unavailability of the laboratory space outside of scheduled class time. In revising the course, our goals were as follows:

- Increase student interest in this required course.

- Intellectually engage students in the lab.

- Expose students to current and relevant techniques.

- Require students to analyze data in depth and draw accurate conclusions.

- Help students see the "big picture" and make connections between concepts.

- Enhance students' ability to effectively communicate their findings.

- Provide an experience more like that in a research lab.

- Relate to lecture, but go beyond verification of lecture material.

\section{THE SOLUTION: A LABORATORY GROUNDED IN INQUIRY}

\section{General Outline of Lab}

In response to the goals and challenges outlined above, we designed an inquiry-based laboratory that employs lab modules. "Science as inquiry" was one of the eight content standards put forth in the National Science Education Standards, where it was described generally to "require that students combine processes 'of science (i.e. observation, inference, and experimentation)' and scientific knowledge as they use scientific reasoning and critical thinking to develop their understanding of science" (National Research Council [NRC], 1996, 105). The standards stated that inquiry was a fundamental component of science education at all levels and suggested mechanisms to promote inquiry-based education. Subsequent arguments for emphasizing inquiry in science education and further analysis of the definition and practice of inquiry have been contributed by multiple groups (Boyer Commission, 1998; NRC, 2000; Sundberg, 1997). In addition, the relationship between inquiry and improved learning has been well documented (Bransford et al., 1999). Although guidelines to include inquiry into teaching laboratories have been put forth (Arce and Betancourt, 1997; Crandall, 1997; Oliver-Hoyo et al., 2004; Sundberg et al., 2000), an exact strategy for immersing a particular course in inquiry is not always obvious. We organized the lab into multiweek modules to provide students sufficient time with each question to engage in the inquiry process from design through communication of results. As discussed in the National Science Education Standards (NRC, 1996), one aspect of "science as inquiry" is that students use techniques and instrumentation that are appropriate for their education level to gather data during the inquiry process. Because many of our students will go on to become career scientists, it was important that the lab modules provided an opportunity for students to learn relevant techniques while pursuing the project at hand.

Each module we developed is introduced with a case scenario that provides a contextual setting for the lab work and introduces the particular questions to be investigated. These opening stories are constructed using established guidelines for writing case studies (Herreid, 1997). Because one of our goals was to provide an experience that was more like a real research lab, the questions are valid scientific questions that might be explored by an independent researcher. Although the exact characters are fictitious, the dramatic element of each story is also realistic as one scenario spotlights a researcher in a biotech company frustrated by an inept boss and unexpected delays in facility remodeling and another tells of a Ph.D. candidate whose graduation is threatened by the possibility of his or her project getting "scooped" by a competitor.

The labs are designed for students to work in groups of four with a maximum of five groups per lab section. Students work in the same groups all semester, so there is maximal efficiency of the group process. The semester is divided into three "wet" lab modules that follow the general outline described in Table 1. These wet labs will be the focus of this paper. There is also a fourth "dry" lab module in which students spend $1 \mathrm{wk}$ at the computer performing the bioinformatics approaches described by Lemmers et al. (2002). In the second week of this dry lab, students discuss the paper, focusing on the bench experiments that tested the predictions made from bioinformatics. This exercise gives students practice dissecting primary literature and is part of a multidepartment effort at UW-L to incorporate bioinformatics throughout the curriculum, which will be discussed elsewhere.

\section{Hallmarks of Inquiry}

The wet lab modules vary somewhat in organization and range from guided inquiry, where the instructor plays a pivotal role in providing both the questions to be asked and the means to obtain and evaluate the answers, to open-ended inquiry, where students are more independent in choosing what to test, designing experiments, and analyzing data (D'Avanzo and McNeal, 1997). As defined in a 2000 NRC report (NRC, 2000, 25), the five necessary components of inquiry education are "(1) learner engages in scientifically oriented questions, (2) learner gives priority to evidence in responding to questions, (3) learner formulates explanations from evidence, (4) learner connects explanations to scientific knowledge, (5) learner communicates and justifies explanations." Within each category, the report defined a spectrum of activities that differed in the level of instructor guidance. The modules designed for Cell Biology satisfy all five tenets of inquiry education listed above, and there is a progression throughout the semester toward more open-ended inquiry projects. The details of each module are discussed later, and the content of each is outlined in Table 2. For two of the modules, students learn the techniques required to answer the questions proposed by the module in the first week or two. During this introductory period, students primarily follow protocols described in the lab manual. In the subsequent weeks, students design and perform their own

Table 1. Lab module components in the manual
1. Overview and table of contents
2. Case scenario to provide context
3. Description of expected product
4. Background information and theory of techniques
5 . Weekly prelab entrance requirements questions
6. Detailed protocols
7. Grading rubric 
experiments using these techniques. In a third module, the instructors design the experiment and procedure that is completed in week 1 . Students then spend 2 wk analyzing the data in an open-ended format. At the conclusion of each module, students are responsible for critically analyzing their data and specifically addressing the questions posed at the beginning of the module. They present their results in a research paper, poster, or formal oral presentation, depending on the module. For each of these graded products, a detailed rubric is administered at the outset of the module (see Supplementary Material). Although each individual rubric is tailored to the specific project, they all evolved from a common template that focused on the five components of inquiry as described above. This organization allows significant student independence and input into the lab exercises while taking into consideration the fairly high enrollment, a relatively small course budget $(\$ 1,000 / \mathrm{yr})$, and very limited access to laboratory space and equipment outside of the regularly scheduled lab period.

\section{Preparing Students for Inquiry}

Because students are performing new techniques, utilizing new equipment, and involved in experimental design and data analysis, it is imperative that they are prepared for each lab period. To this end, prelab assignments, called entrance requirements, were adapted from a presentation heard at a small teaching conference (P. Parker, personal communication). These assignments consist of three to five questions that challenge students on the theory behind the experiments, details of instrument usage, necessary calculations, or analysis of sample data. Students keep one copy of their entrance requirements and another is collected at the beginning of the lab period and graded out of three points. The correct answers are covered during the prelab lecture so that students have the necessary information to successfully complete the lab. The prelab assignments are called entrance requirements because they are designed to make students wrestle with concepts that are important to understand at the outset of lab. Furthermore, in their original application, students who failed to complete the assignment were denied access to the laboratory for that period. Due to room and time constraints, these students were unable to make up the lab and could not fully contribute to the rest of the lab module. Also, it was difficult to determine at a glance whether students who had completed the assignment actually had correct answers. Instead, we chose to penalize noncomplying students by giving them a zero for the assignment and an additional loss of five points. This appears to be a substantial motivator, as we typically have one or two students at most who forget to complete a set of entrance requirements per semester. The entrance requirement moniker helps to emphasize to students the penalty involved.

\section{LAB MODULES AT A GLANCE}

\section{Module 1: Investigating the Cellular Distribution and Biochemical Properties of Earthworm Alkaline Phosphatase (Table 2)}

Case Scenario. The researcher (student) is working for a biotech company that has developed a potential breakthrough drug to treat influenza. However, in the intestines of mammals, a key phosphate group is cleaved, thereby rendering the drug inactive. In the story, the company is looking for a way to prevent digestion of the drug by intestinal alkaline phosphatases (ALPs). The company's vertebrate animal facility is closed for renovation, so the researchers need to find a suitable invertebrate for experimentation. The researcher's (student's) charge is to determine whether earthworm ALP shares enough similarities with mammalian ALP that earthworms could be used as a model organism. Specifically, ALP localization in the earthworm and its biochemical properties are studied.

Week 1. To qualitatively determine where ALP is found in the earthworm, frozen tissue sections are obtained with a cryotome. Each student cuts his or her own section and uses napthol AS-MX and Fast Blue RR (Kit 85L-1; Sigma Chemical, St. Louis, MO) to histochemically stain for ALP. Sections are taken from four to five different areas along the anterior-posterior axis of the worm. Slides are prepared this week and analyzed in weeks 2 or 3 using compound microscopes equipped with digital cameras.

Week 2. To quantitatively determine ALP activity in different earthworm tissues, students dissect earthworms, create tissue extracts, and perform an ALP activity assay using the substrate p-nitrophenyl phosphate. The assay is colorimetric, and results are obtained quickly using a microplate reader, allowing students to calculate simple activity. During this week, the instructor facilitates a lab discussion on possible experiments that would test whether earthworm ALP is biochemically similar to mammalian ALP. By asking follow-up questions, the instructor helps students verbalize which aspects of the protein structure/function relationship an experiment affects. Each group then discusses on their own and decides on a biochemical property to test. Because the manual provides them information on the distribution, heat stability, $\mathrm{pH}$ dependence, and divalent cation dependence of mammalian ALP, groups test an aspect of one of these properties.

Week 3. This week, each group performs a different experiment based on information given to them about mammalian ALP characteristics. As part of the entrance requirements, each student comes prepared with a proposed experimental design. The instructor visits with each group to review and improve these before experimentation commences. Typically, one group will again test earthworm ALP activity in different tissues. In addition to an enzyme activity assay, they perform a Bradford assay to calculate total protein concentration, which allows them to determine specific activity instead of just simple activity. Other groups will measure specific activity of worm ALP from one tissue under different conditions. For example, one group will perform the activity assay under a range of $\mathrm{pH}$ conditions to determine optimal $\mathrm{pH}$. Another will assess ALP activity after a preincubation period at different times or different temperatures to compare heat stability of worm ALP to that of mammalian ALP. Finally, one might determine whether worm ALP requires divalent cations to be maximally active, so the enzyme activity assay is performed with varying concentrations of EDTA.

Product. To facilitate the dissemination of information, each group is responsible for calculating specific activities for their 
particular experiment, and after review by the instructor, a packet with the final specific activity numbers for every experiment is distributed to each student. Each group then incorporates these data from all groups with their own data into a formal, written report. The report presents and synthesizes the data from the histochemistry experiment, the specific activity experiments performed by all groups in week 3 , and often their simple activity results from week 2 . The papers are an abbreviated scientific paper consisting of a short introduction, a considerable results section with each piece of information represented as a figure or table, and a short discussion. The requirement to present and consider the findings from all groups in week 3 provides students with much more information than they could obtain within their own group in the allotted time. Therefore, students must synthesize considerable information to answer the question: Are earthworms a suitable model system to study ALP?

Level of Inquiry. This module starts as guided inquiry and develops into open-ended inquiry (see D'Avanzo and McNeal, 1997 for definitions). In the histochemistry portion, students are provided explicit instructions to create their slides and are assigned segments of the earthworm to section. However, the analysis of their histochemistry data is much more open-ended. For example, we have found no published diagrams of cross-sections of earthworm pharynx, crop, or gizzard, so students must interpret their crosssections of these regions by looking at diagrams of longitudinal sections and using their experience dissecting whole worms. In the final week, students choose their own question and design the experiment, adapting the procedure they have learned. The students' initial experimental designs in their entrance requirements are usually oversimplified, or contain significant design flaws, or both. The instructor discusses this initial experimental design with each group individually to ensure that the design actually tests their question and that the proper controls are included. Data analysis of enzyme activity is also relatively open-ended. Students know they need to calculate specific activity and are provided with a general formula for specific activity. However, they are not provided explicit instructions on how to convert their data into a form that fits the specific activity equation. Finally, students are forced to wrestle with imperfect data and conclude whether or not earthworms are a suitable model organism for the proposed studies. Although the data are highly consistent from semester to semester, they do not all neatly support the same conclusion. Hence, students must prioritize experimental findings with regard to the scenario provided.

\section{Module 2: Determining the Effects of Antitumor Drugs on the Cytoskeleton (Table 2)}

Case Scenario. The researcher (student) is a slightly frustrated graduate student months away from receiving his or her Ph.D. who learns that another lab is working on the same three chemicals that display antitumor activity in cultured cells. Before presenting the work in a poster at an international conference in Italy and, ultimately, publication, the student is told to quickly obtain some insight into the molecular basis of drug action. On the basis of published literature on previously studied antitumor chemicals, the student hypothesizes that the cytoskeleton might be disrupted by the chemicals that he or she has identified. To investigate this, the researcher sets out to observe the cytoskeleton in both untreated and drug-treated cells.

Week 1. To determine whether the newly identified chemicals (known to the instructor as colchicine, cytochala$\sin \mathrm{D}$, and paclitaxel) affect the cytoskeleton, students triplestain cultured Chinook salmon embryos cells (CHSE-12 cells) using indirect immunofluorescence to label microtubules, fluorescent phalloidin to label actin filaments, and $4^{\prime}, 6-$ diamidino-2-phenylindole dihydrochloride (DAPI) to stain the DNA. Within each lab group of four individuals, two students label untreated control cells, while the others stain drug-treated cells. Because there are five groups and only three drugs, two of the drugs are used twice. However, their concentration is varied between groups, which alters the severity of the results. Slides are prepared this week and analyzed the following two weeks.

Weeks 2 and 3. Students spend the next $2 \mathrm{wk}$ analyzing their slides using one of two research-grade light microscopes equipped with fluorescence and digital cameras. Each group is allowed an hour of microscope time during lab each week to first determine whether and how the cytoskeleton is affected in their treated cells and to then take digital micrographs documenting their findings. The students are responsible for obtaining at least one high-quality image representing each of the following for both control and treated cells: the organization of actin filaments, the organization of microtubules, the general shape and position of the nucleus, and the overall morphology of the cell, using either phase contrast or differential interference contrast microscopy.

Product. The week following data collection, each group presents its findings as a poster that is similar in quality to one presented at a scientific meeting. Students are graded on the quality of their figures (the labeled digital images); the clarity, conciseness, and completeness of their writing; and the accuracy of their conclusions.

Level of Inquiry. Due to time and budget constraints, the instructor plays a larger role in guiding the work in this module than the others. The goal of this module is more for students to learn a fundamental cell biology technique than to engage the students in true inquiry. The instructors choose the drugs, concentrations, and length of treatment. Students follow an explicit protocol to perform the labeling. The novel chemicals are actually well-described disrupters of the cytoskeleton that reliably cause distinct effects on the treated cells. Thus, an argument could be made that this module involves a minimal amount of student inquiry, and, in fact, we previously have taught these techniques as a demonstration lab. However, the case scenario helps to make the lab investigative for the students and not simply validation. Furthermore, data analysis is truly investigative for the students because the module precedes lecture coverage of the cytoskeleton. As students analyze their slides, they discover for themselves, with subtle instructor input, the organization of both normal and disrupted cytoskeletons. Importantly, they are expected to predict how the observed change in cytoskeleton would adversely affect cell growth 
and division. Establishing this link requires that students reconnect to the original purpose of the experiment and its big picture and independently explore the cellular mechanisms of cell division prior to lecture on that topic. Occasionally, students do not obtain the predicted results. In these cases, the important point is for the students to analyze and interpret their data accurately, emphasizing the inquiry aspect rather than validation of expected observations.

\section{Module 3: Investigating Whether Everyday Products Affect Eukaryotic Cell Growth and Division (Table 2)}

Case Scenario. A collaboration with a fictitious local company that is focused on cancer research provides the context for this module. In an effort to find novel compounds that might affect the eukaryotic cell cycle, a partnership with the UW-L Biology Department has been established. As part of the Cell Biology class, students spend 3 wk testing whether a substance of their choice affects cell growth and division of insect cells. Students are encouraged to draw upon their own knowledge, the Internet and, in particular, the scientific literature, to choose a substance that could logically be hypothesized to affect the cell cycle. As part of the story, students with results deemed interesting by the company are promised a modicum of fame and fortune. The specific goals are to determine whether the treatment affects cell growth, cell division, or the repertoire of proteins present in the cells.

One Week Prior to the Module. Instructors facilitate a class discussion of chemicals, drugs, foods, environmental contaminants, etc., that students think might affect the cell cycle. Typically, students have many ideas based on products that are commonly used, new "fad" products, or allegedly dangerous substances. Computers are available so that groups can perform Internet searches, including using primary literature databases, to assist them in narrowing their initial list and ultimately choosing one substance to test in the module. Prior to leaving, students receive instructor approval for their substance and are responsible for supplying the substance in the following week.

Week 1. Students learn how to maintain a sterile culture of Sf9 cells, make a fresh passage of cells, and count cells via a hemocytometer. Their substance of choice is solubilized if necessary, filter-sterilized, and diluted in culture media to concentrations deemed physiologically relevant to the weight of cells that will eventually be used in a doseresponse experiment. Students are responsible for providing information on chemical structure to help determine what type of solvent to use, and also on typical doses for humans that can then be scaled down appropriately. The instructor reviews the experimental design and relevant calculations for each group.

Week One-and-a-Half. Outside of their scheduled laboratory period, students are required to come in and set up their dose-response experiment. This involves determining the number of cells in their flask and diluting the cells to the appropriate concentration in fresh media for plating in 12well plates. They then add either media alone (for controls) or the appropriate treatment concentration diluted in media from week 1. Each group tests three concentrations of their selected treatment, and each concentration is tested in triplicate.

Week 2. To determine whether the treatment affected cell division, the number of cells per milliliter is determined for each well using a hemocytometer, and the average is taken for each experimental condition (control and the three concentrations of treatment). To determine whether cell mass (growth) has changed, a Bradford assay is performed to calculate the protein concentration in each well and the averages obtained. Finally, to investigate whether the treatment has elicited changes at the protein level, cells from each experimental condition are lysed and subjected to sodium dodecyl sulfate-polyacrylamide gel electrophoresis (SDSPAGE). Next week, the banding patterns are compared and the molecular weight is determined for any band that is not found under all circumstances explored.

Week 3. This week, near the end of the semester, provides time for students to perform the necessary calculations from all the raw data obtained the week before, to take digital images of their Coomassie-stained SDS-PAGE gels, to synthesize all the information and make conclusions, and search for primary literature that provides a context for their findings and may provide insight into the molecular basis of action.

Product. The week following data analysis, each group presents its findings in a formal oral presentation using Microsoft PowerPoint. They are responsible for providing a detailed introduction on the chosen treatment, including its chemical composition, history, previous experiments or clinical studies, and why it was chosen. They must present all of their data as polished figures and make logical conclusions. Finally, a possible model is presented that connects the treatment to the cell cycle. The model should be consistent with the group's data and suggest possible molecular targets. If treatment has no effect, a model consistent with the hypothesized effects and the scientific literature is acceptable. The overall organization of the talk, the quality and effectiveness of the slides, and the delivery are all considered in grading as well as the quality of data, accuracy of conclusions, and the depth of information.

Level of Inquiry. Students work primarily independently in this final module, which tends toward a true open-ended investigation (D'Avanzo and McNeal, 1997). Because lab groups continually choose substances that have not been selected in the past, the outcomes are usually unknown to both instructor and student. Students are provided with guidelines and protocols to help them perform the experiments, but must make decisions as to how the protocols are applied. Students are responsible for using the primary literature to help them interpret their results. As much as can be expected in a 4 -wk period, the students are conducting real research.

In summary, each of the modules described here satisfies the requirements for inquiry (NRC, 2000), and there is a progression from more reliance on the instructor to greater student independence during the semester. This progression is best represented in three of the five aspects of inquiry. First, the exact questions pursued by the students are posed 
by the instructor in the first two modules, whereas the students generate their own questions in the last module. Second, the requirement for students to connect their explanations to scientific knowledge is a central theme, but the level of responsibility increases with each module. In the first module, students are asked to make direct comparisons with mammalian data that are already provided in the lab manual. In the next module, they must explain how changes in cytoskeletal organization might lead to defective cell division, which requires reading and analysis of textbook information not yet covered in lecture. Finally, in the last module they must effectively search literature databases and find research articles that support their findings, or provide the most current data on the molecular mechanism of action of their chosen substance, or both. The third aspect of inquiry that varies throughout the semester is the end products themselves. The first module includes very specific instructions for a product largely focused on results, whereas by the last module there are fewer guidelines but higher expectations for the introduction, background, and conclusions, in addition to data analysis and presentation in professionalstyle figures.

\section{DEVELOPMENT OF AN ASSESSMENT STRATEGY}

The importance of assessing pedagogical change is clear, but the mechanism by which one does so is not always obvious (Tanner and Allen, 2004). As instructors, we wrestled with which kind of information would best inform us whether the lab module format was a successful model for inquiry-based education. We did not want the assessment to drive the pedagogy. Because revisions to the lab were gradually instituted over multiple semesters, it was impossible to conduct any accurate prerevision/postrevision comparisons. Lab exams are not given, so it was not practical to use strictly lab-based, objective, summative questions. In the end, we decided on three approaches to assess the lab modules: 1) surveys that ask students to compare the lab with other lab courses that do not use the module format, 2) summative data comparing student performance on the first lab module report with the last lab module, and 3) results of a national standardized test.

\section{Development of Survey Tools}

We also had questions in regard to developing the student survey instrument. Should we obtain quantitative data directly addressing our goals, or should we elicit subjective comments in the students' own words to avoid our own natural bias? What eventually evolved as the official assessment tool largely meets both of those needs, because it was designed in part by student free-response comments. Development of the tool began with administering a very openended, free-response assessment of the Cell Biology laboratory in semesters while the laboratory revisions were in progress. Students were asked to compare their lab modules experience with single-week labs with which they might have been more familiar. In this preliminary assessment, the vast majority of students ( $\sim 85 \%$; data not shown) responded that they preferred multiweek modules over single-week labs. Furthermore, many of those who favored the module organization gave one or more specific reasons. After two semesters of collecting this free-response data from students, their replies were loosely categorized and quantitated. Interestingly, the same types of responses, perhaps with slightly different wording, were emerging from multiple students over the two semesters. Students' reasons for favoring the lab modules were monitored for another two semesters until it was clear that the majority could be categorized under one of seven descriptions. Remarkably, most of these were in agreement with the instructors' learning goals. The instructors then used the responses obtained from the students to generate a quantitative assessment.

It should be noted that during the period that free response data were collected, a small percentage of students wrote that they preferred single-week labs over lab modules. Their comments supporting this choice almost entirely fell into two categories. First, many of them liked single-week labs because they were conceptually simpler and they required less effort. From an instructor's perspective, these types of responses also place lab modules in a more favorable light, even if that was not the students' intent. The second most common response was an expression of frustration over the time invested preparing for the lab and coordinating schedules with those of other group members to complete projects. Increased time commitment is a noted consequence of inquiry education (Oliver-Hoyo et al., 2004). Because it did not reflect on the learning environment in lab per se, it was not included in the quantitative assessment.

In the quantitative assessment, previous students' top seven positive characteristics of lab modules were listed, with wording similar to that used by the students. For four semesters, students were asked to check the box next to any statement they felt was true about the multiweek module format. In addition, they were asked to rank the top three in order of importance to them (Figure 1). Because we were concerned that the yes/no aspect of this assessment may not accurately reflect the range of student attitudes toward the lab, the same questions were asked in a fifth semester, but this time with five possible responses ranging from "strongly agree" to "strongly disagree" (Table 3).

One exception to the student-driven nature of the assessment tool is the inclusion by the instructors of an eighth statement addressing oral and written communication skills. Communication skills are an integral part of inquiry-based education, as it models true research in which dissemination of information is essential (NRC, 2000). Despite our convictions that communication was a major focus in the Cell Biology laboratory, it had never been mentioned in the free-response student assessments. We reasoned that although students might recognize the importance of communication, they rarely enjoyed assignments that forced them to write or do oral presentations, and therefore might not consider communication skills when making favorable comments about the new lab. Improving communication skills was one of our primary goals of the lab, and we wanted to assess the success of the module format in this area.

\section{Assessment Results}

The results from the two types of quantitative surveys were remarkably similar. If the percentage of times that a lab attribute was checked (Figure 1A) is compared with the sum of the strongly agree and agree categories (Table 3 ) for that item, the same trends are seen. Both sets of data show that 

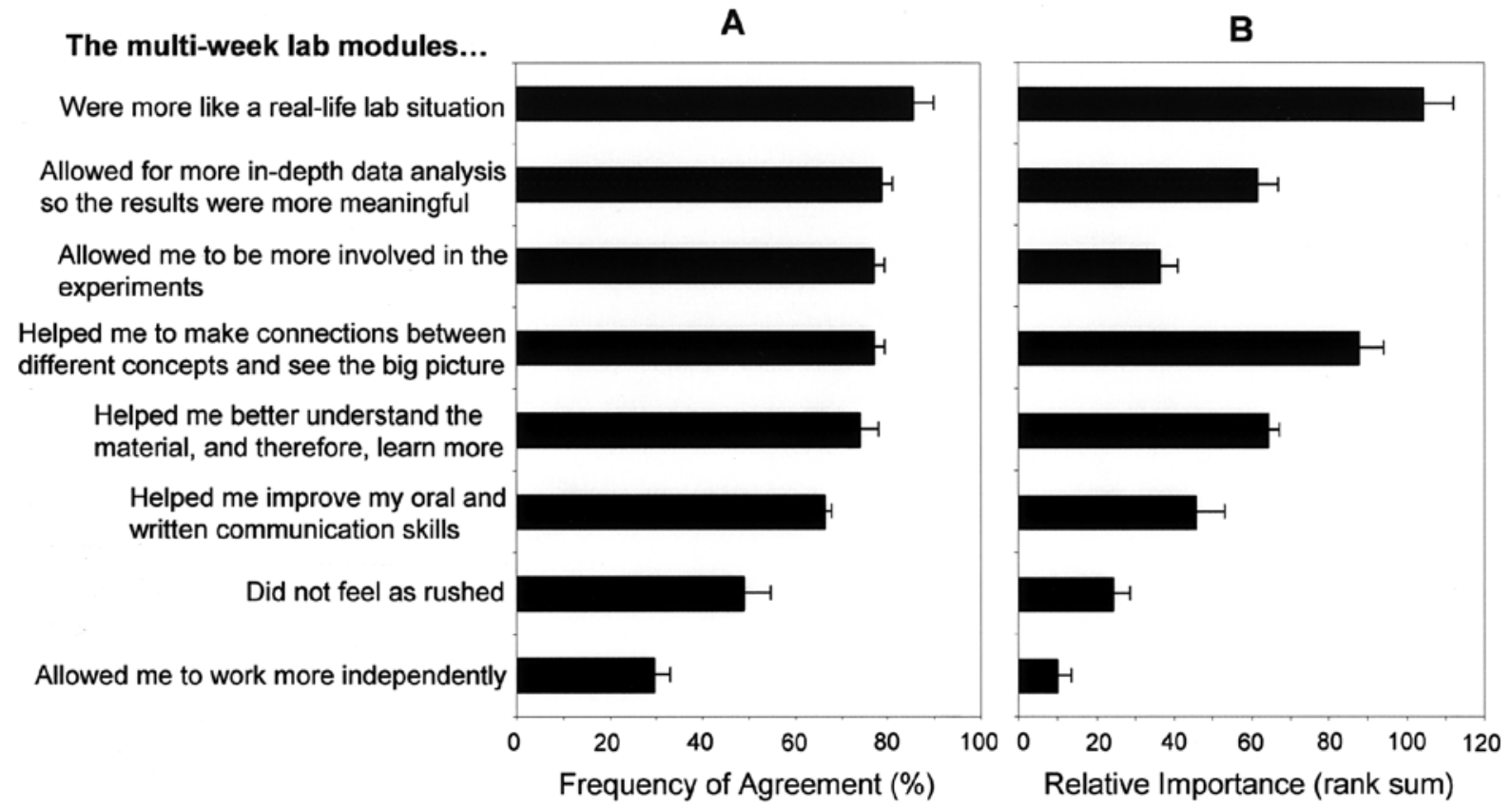

Figure 1. Students select and rank positive attributes associated with module-based lab. A) In an end-of-the-semester assessment, students were asked to check the box next to any of the eight statements listed above that were representative of their experience in the module-based lab. These statements were derived primarily from a free-response assessment administered to students in previous semesters. In the survey tool, the students are asked to compare the module approach to single-week labs in their other courses. B) Students were then asked to rank the three attributes that were most important to them out of those that they had checked (if applicable). Student rankings were assigned the following values: top reason $=3$, second reason $=2$, third reason $=1$. The sum for each statement was then calculated. The results are reported as mean \pm s.e.m. for four semesters $(A=$ mean percentage, $B=$ mean rank sum). The percentage of times checked data $(A)$ provides information on whether students found the item had any value. The rankings (B) provide data about which items the students found most important.

students felt the module approach positively affected their lab experience in several ways. In trying to determine which of the attributes of lab were most helpful, the student rankings (Figure 1B) provide a clearer picture than the five category data (Table 3).

\section{Lab Modules Provide an Inquiry Experience}

Six out of the eight potentially positive attributes (Figure 1A) were selected by at least two-thirds of the students, indicating that the majority of students felt that these were positive aspects of the lab module approach. More than $80 \%$ of students indicated agreement on these same items (Table 3). Two attributes ("did not feel as rushed" and "allowed me to work more independently") fell below the $50 \%$ mark. The most commonly selected (85\%; Figure 1A) and highestranking (Figure 1B) statement was that the modules "were more like a real-life lab situation," demonstrating that students felt that the lab module format created an experience that was more like research, which was one of our goals. It also suggests that the stories placing the experimentation into a context might be beneficial. This was one of the few items in which the checking/ranking system (Figure 1) supported a conclusion different from that of the five-choice system (Table 3). More students strongly agreed with five of the other statements than with the statement that labs were more like real life (Table 3). This may be due to the fact that there is only one semester's worth of data for the five-choice system.
Four of the statements were checked by $74 \%-79 \%$ of the students (Figure 1A). The higher-ranked score (Figure 1B) and strong agreement (Table 3) for "helped me make connections and see the big picture" indicates that students felt this was the most important of the four. Assisting students to see the big picture was another primary aim of this revision project, and an essential feature of inquiry education. In the most student-active form of inquiry, the learner must "connect explanations to scientific knowledge" (NRC, 2000, 29). In traditional lab setups, students learn techniques in isolation, which is completely contrary to real research in which multiple techniques and approaches are used to investigate a single question. Furthermore, the molecular nature of modern cell biology is so detailed and seemingly abstract that students often have a hard time seeing the forest for the trees. We designed the ALP and cell growth modules so that students needed to apply several approaches to answer a central question. This approach, coupled with the demand for comprehensive data analysis, appeared to counterbalance these inherent obstacles.

Most (79\% checked, $85 \%$ agreed) students responded that the modules "allowed for more in-depth data analysis so the results were more meaningful," and students also ranked this attribute highly (Figure 1A,B; Table 3). A hallmark of inquiry-based education is that evidence is of utmost importance, and the students are allowed to generate explanations based on their data (NRC, 2000). We continuously emphasize that project conclusions must be consistent with 
Table 2. Outline of semester and module content

\begin{tabular}{lllll}
\hline Module & Week & Techniques used/activities & Data gathered or analyzed & Aspects of inquiry \\
\hline
\end{tabular}

Mastering the micropipetter, etc.

Investigating the cellular distribution and biochemical properties of ALP in earthworms

Bioinformatics/primary literature analysis dry module of antitumor drugs on the cytoskeleton
Determining the effects
1

Practice using micropipetters, plate readers, and Microsoft Excel

2 Histochemistry using frozen tissue sections of earthworms

3 Tissue dissection, preparation of enzyme extracts, ALP activity assay; students work on experimental design for week 4 .

4 Instructor reviews experimental design with each group; week 3 techniques \& Bradford assay
Generate a standard curve; NA each individual performs lab

Slides are prepared this week \& analyzed weeks 3-4; different tissue per group

Figure simple enzyme activity; all groups analyze multiple tissues

Assess specific enzyme activity; each group tests a different variable

\section{a eart}

Week 4: Experiments designed to compare earthworm ALP with published information on mammalian ALP.

1. At what $\mathrm{pH}$ does earthworm ALP have maximal activity?

2. Is earthworm ALP temperature stable?

3. Does earthworm ALP require divalent cations for maximal activity?

4. What tissues have the highest ALP activity?

5 Instructor reviews ALP data from groups and disseminates info; bioinformatics exercises

6 Connect bioinformatics re- Analyze all the figures in sults to bench experiment a primary literature paper data

7 Indirect immunofluores- Slides are prepared this cence and fluorescent label- week and analyzed in ing of treated and un- weeks 8-9 treated Sf9 cells chooses a substance for

Investigating whether everyday products affect eukaryotic cell growth and division
8-9 Use light and fluorescent microscopy and digital cameras to analyze slides. Each group has $1 \mathrm{~h}$ exclusive use/week

10 Poster session; each group week 11

11 Passage Sf9 cells, get test substance into solution, filter sterilize, and dilute in media

11.5 Set up dose-response ex- NA periment

12 Cell counts with hemocytometer, Bradford assay, SDS-PAGE

13 Gel documentation, extensive literature searches

Digital images documenting cell morphology, characteristics of nuclei, \& cytoskeletal organization

Students gather information on potential substances to test

Info on chemical structure (solubility) \& typical dosage of substance is reviewed

Determine cells $/ \mathrm{mL}$, total protein concentration

Analyze SDS-PAGE, construct a model for data

14 Oral PowerPoint presenta- NA
Weeks 8-9:

1. Observe and document many cellular features in untreated cells, including cytoskeletal organization, prior to lecture coverage.

2. Determine whether and how treated cells differ from the untreated. If multiple differences exist, students hypothesize whether or not they are all direct consequences of treatment or might some be indirect.

3. A connection between observed changes and mitosis and cytokinesis is made.

Weeks 10-11: Each group picks a test substance based on interests, societal trends, and scientific literature, and determines relevant dosages to test.

Weeks 11.5-13: The following questions are addressed by experimentation:

1. Was cell division affected?

2. Was cell growth/size affected?

3. Did treatment affect synthesis, degradation, or modification of secreted (in media) or cellular proteins? 
their data; there is not a preconceived conclusion that might require one to disregard data. The multiple-weeks and multiple-approaches format probably also contributes to the students' ability to analyze data more in depth.

Although it was fifth in the number of students who checked it $(74 \%)$, the high student ranking of "helped me better understand the material, and therefore, learn more" indicates that for those students who checked this attribute, it was one of the most important. The similar percentages of agreement between the top five attributes make this sort of distinction difficult (Table 3). Thus, the check/rank system may provide more useful information for formative assessment. Four semesters of student rankings clearly show that increased understanding and learning was more important to them than greater involvement in the experiments. However, more students agreed ( $91 \%$ versus $82 \%$, Table 3 ) that the modules allowed them "to be more involved in the experiments," which would be expected with this format. This involvement shows that students feel intellectually engaged in lab, which was one of our objectives.

Although the idea had never been expressed by previous students in the free-response style evaluations, students felt that the modules "helped me improve my oral and written communication skills" (66\% checked, Figure 1A; $83 \%$ agreed, Table 3). Communicating and justifying explanations are the fifth and final essential feature of inquiry education (NRC, 2000) and a core component of the modules. Being forced to practice three different forms of communication (scientific report, poster, and oral PowerPoint presentation) provides ample opportunities to improve this skill. Two characteristics of the revised lab that had been routinely mentioned by former students and, therefore, placed on the assessment did not score highly on this assessment. Around half $(49 \%$ checked, Figure 1A; $65 \%$ agreed, Table 3) of the students still indicated that they "did not feel as rushed" with the modules compared with other labs. We hypothesize that this number is very dependent on the preparedness of the individual student and the other group members with whom he or she works. In addition, many of the lab periods are filled with work, so that in an individual lab, students can still feel rushed. Only 30\% checked and $41 \%$ agreed that they could work more independently in the modular format, and that is likely because they always work in groups and likely depend on their other group members. We suspect that students who indicate they can work more independently are referring to independence from the instructor or manual. Unfortunately, this assessment statement may be too vague to interpret accurately.

\section{Impacts on Student Learning}

The specific focus of the survey assessment tool was to determine whether the lab module format provided a learning environment rich with inquiry. However, the overarching goal of any pedagogical reform is to improve student learning. We have three lines of evidence that suggest the revised Cell Biology course has positively influenced student learning. First, for five semesters, students scored significantly higher on the last module report than on the first (Figure 2; $p<0.0005$, paired samples $t$-test, each semester). This is a valid comparison because the graded products for the two modules both focus on data analysis and making accurate conclusions from the data. In addition, the grades in both modules are derived from detailed rubrics, which although specific to the module content, are based on similar principles of inquiry and communication. The student performance is better on the final project even though the students have less guidance than on the first module report. To help them prepare for the first report, past examples of good papers are provided and the instructors lead a discussion helping students interpret the data. Neither of these is done for the last report. In the last module, students are responsible for a greater amount of the experimental design, must use outside resources, and have less to time to prepare the final module product than the first. This significant improvement in performance supports the students' assertions that the module format helped them understand the material better and improve their communication skills (Figure 1; Table 3). Although we cannot exclude mere repetition and practice as an explanation for at least part of the improvement documented in Figure 2, it is unlikely, since the scientific questions and specific techniques are dramatically different in the two modules that are compared. We believe that these data show an improvement in students' inquiry skills over the course of the semester with the lab module approach.

A second line of evidence comes from results of a nationally standardized test. Seniors in the Department of Biology were required to complete the Major Field Test in Biology (Educational Testing Service, 2003) for the first time in May 2004. This group consisted of students who had taken Cell Biology sometime during the past four semesters. The exam is divided into four topics: cell biology; molecular

Table 3. Analysis of module approach ${ }^{a}$

\begin{tabular}{|c|c|c|c|c|c|}
\hline The multiweek lab modules... & $\begin{array}{l}\text { Strongly } \\
\text { agree }\end{array}$ & Agree & $\begin{array}{c}\text { Neither } \\
\text { disagree/agree }\end{array}$ & Disagree & $\begin{array}{l}\text { Strongly } \\
\text { disagree }\end{array}$ \\
\hline Were more like a real-life lab situation & 36.4 & 50.6 & 10.4 & 1.3 & 1.3 \\
\hline Allowed for more in-depth data analysis so the results were more meaningful & 41.6 & 44.1 & 10.4 & 2.6 & 1.3 \\
\hline Allowed me to be more involved in the experiments & 46.1 & 44.9 & 7.7 & 1.3 & 0 \\
\hline Helped me to make connections between different concepts and see the big picture & 46.1 & 42.1 & 11.8 & 0 & 0 \\
\hline Helped me better understand the material, and therefore learn more & 40.3 & 41.5 & 14.3 & 2.6 & 1.3 \\
\hline Helped me improve my oral and written communication skills & 40.3 & 42.8 & 13.0 & 3.9 & 0 \\
\hline Did not feel as rushed & 29.9 & 35.1 & 19.5 & 13.0 & 2.6 \\
\hline Allowed me to work more independently & 20.8 & 20.8 & 38.9 & 18.2 & 1.3 \\
\hline
\end{tabular}

${ }^{a}$ The percentage of students responding in each category is shown. $\mathrm{N}=78$ students. 


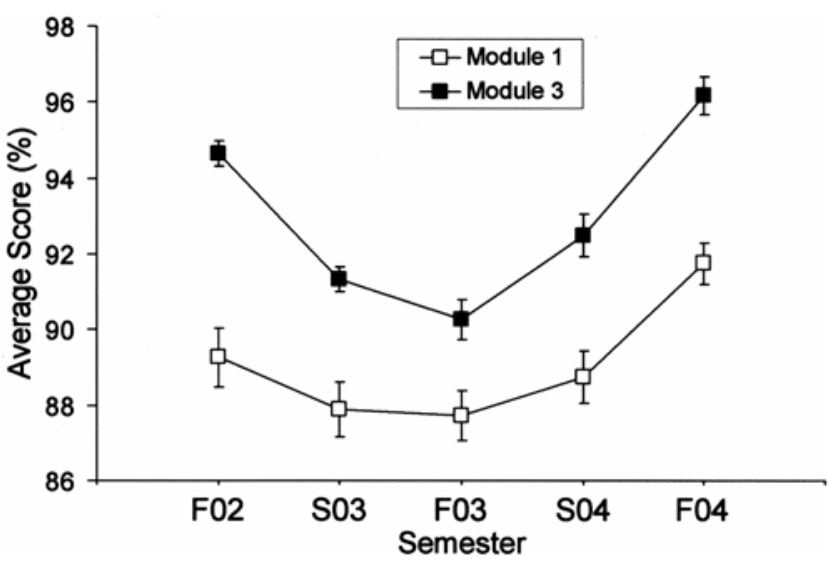

Figure 2. Student performance improves over the course of the semester. The average score on the final assignment (Module 3, solid squares) was significantly higher than the score on the first module (Module 1, open squares) in each of the five semesters that the module approach was fully implemented $(p<0.0005$, paired samples $t$-test). Mean \pm s.e.m. are plotted. F02 $=$ Fall 2002, S03 = Spring 2003, etc. $n>70$ students each semester.

biology and genetics; organismal biology; and population biology, evolution, and ecology. Our students scored within the 70-75th percentile in Cell Biology, which was significant for two reasons: 1) they scored 2 standard deviations higher than the national average, and 2) the Cell Biology subscore was the highest of the four topics (the next highest was at the 55-60th percentile). It should be mentioned that the other three areas of the exam are also well represented in our core curriculum. Hence, our students are learning and retaining Cell Biology content.

A final line of anecdotal evidence consistent with the student responses to the survey tool is that we have observed a marked improvement in students' ability to make connections between concepts and analyze and defend data over the past four semesters. Prior to the complete laboratory revision, students would complete the prescribed calculations and present data in an appropriate format, but largely failed to demonstrate deeper understanding or broader implications of the work. It was rare that a group met instructor expectations in their final report, and certainly no one exceeded them. In contrast now, the majority of final products are of excellent quality both in the content and conveyance of ideas. In fact, we are considering increasing expectations on the grading rubrics to reflect increased student achievement. These improved abilities are attributed to the inquiry approach, as well as to detailed rubrics and changing curriculum in courses that precede Cell Biology. Although subjective, this evidence further supports the student claims that have been documented through the assessment tool.

\section{Prelab Assignments Improve Student Preparedness}

Students were asked whether or not the prelab entrance requirements made them better prepared for lab. Eighty percent of students answered positively, with another $13 \%$ replying "Maybe" (Figure 3). Students who fell into this second class often remarked that some entrance requirements were more useful than others. Particular weeks in lab

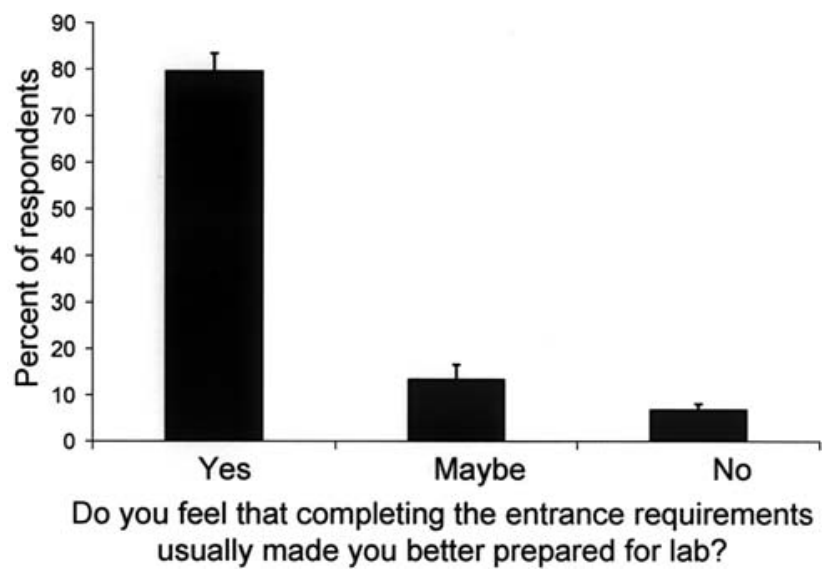

Figure 3. Entrance requirements help prepare students for lab. In an end-of-the-semester assessment, students were asked to respond Yes, No, or Maybe to the question, "Do you feel that completing entrance requirements usually made you better prepared for lab?" The results are reported as mean percentage \pm s.e.m. for four semesters. An overwhelming majority of students $(79.7 \% \pm 3.7 \%)$ reported "Yes," with another $13.4 \% \pm 3.2 \%$ responding "Maybe." A small percentage, $6.9 \% \pm 1.3 \%$, responded "No."

are busier or involve more calculations than others, and prior to instituting entrance requirements it was typical for one or two groups per lab section to have to stay 30 to $60 \mathrm{~min}$ after the scheduled end of lab during these weeks. Anecdotally, it has been our experience that students are much better prepared with entrance requirements, and it is rare that a group has to stay late. Furthermore, students seem to pay more attention to the prelab lecture in which the instructor reviews the relevant calculations or proper experimental controls, perhaps because they have wrestled with these ideas while completing the entrance requirement.

\section{Students Report Improved Critical Thinking Skills}

Making connections, seeing the big picture, more in-depth data analysis, and deeper understanding of material suggest that critical thinking skills were enhanced by the lab module format. Improving critical thinking skills is one of our main goals for the lecture portion of the course, and students' perceptions of their critical thinking were assessed in a separate lecture survey tool. Students were asked whether their critical-thinking/problem-solving skills improved, stayed the same, or worsened over the semester after being given an example of what these terms mean. An average of $79 \%$ of students replied that these skills improved while taking Cell Biology, with $21 \%$ reporting no change (Figure 4). The improved student performance on the last module (Figure 2) supports their self-assessment of improved critical thinking.

When asked to comment on their response to the critical thinking question, the same remarks were echoed again and again. A sampling of statements is listed below.

"Learning how to apply 'information' helps in knowing how to find our own answers to questions we might have later. Regurgitation won't help us design and run our own experiments to find answers." 


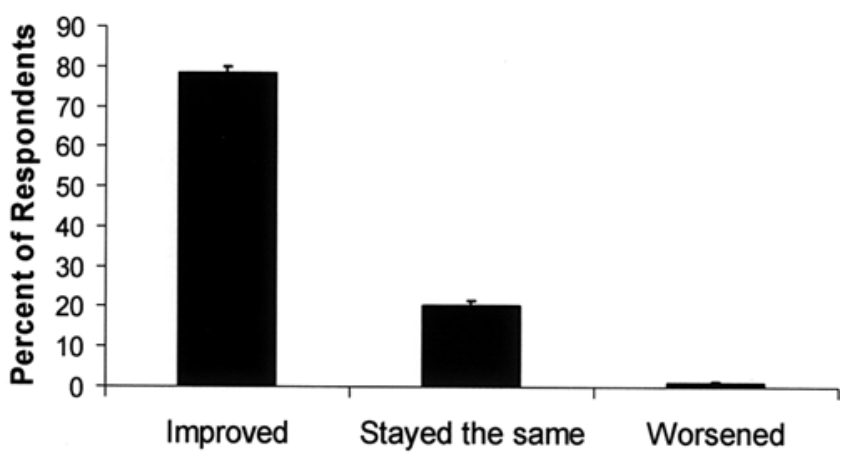

How do you think your critical thinking/problem solving skills have developed over the course of this semester?

Figure 4. Students report improved critical thinking skills after completing Cell Biology. In an end-of-the-semester assessment, students were asked, "How do you think your critical thinking skills have developed over the course of this semester?" The results are reported as mean percentage \pm s.e.m. for four semesters. A large percentage, $78.6 \% \pm 1.4 \%$, of the students reported that their critical thinking skills had improved; $20.4 \% \pm 1.2 \%$ replied that their critical thinking skills had stayed the same; while $1.1 \% \pm 0.4 \%$ marked that their critical thinking skills had worsened.

"Being able to apply the material to new situations shows that you have a good understanding of the subject matter."

“Biology situations aren't always as clear-cut as the problems we worked on in class - you have to think critically, look for similarities, and make connections. I will remember this stuff a lot longer for sure."

\section{Students Report Increased Interest in Cell Biology after Completing Course}

As with critical thinking, many of the goals we hoped to achieve with the revision of the Cell Biology course involved changes in both the lecture and laboratory portions of the class. One goal that was fundamentally important to the entire undertaking was to increase interest in the field of cell biology. Because the course is required for the major, students are forced to take it despite their interest level. This problem was compounded by the particularly poor reputation the course had earned over the years preceding its revision. On the end-of-the-semester lecture evaluations, students are asked to rate their interest in cell biology both prior to taking this course and at the completion of this course by choosing from four options: strong interest, some interest, indifferent, or strong dislike. The data show a significant increase in student interest in cell biology after taking the course $(p<$ 0.0005 , Pearson chi-square test). Prior to taking the class, only $48 \%$ of respondents marked that they had either strong or some interest in cell biology, but $88 \%$ reported interest after the course (Figure 5). An even greater disparity was seen prior to Fall 2002, when more students began the semester with negative attitudes toward the course, again, probably due to the course's unfavorable history. The success of our efforts to increase interest can have short-term and long-term consequences such as making the semester more enjoyable

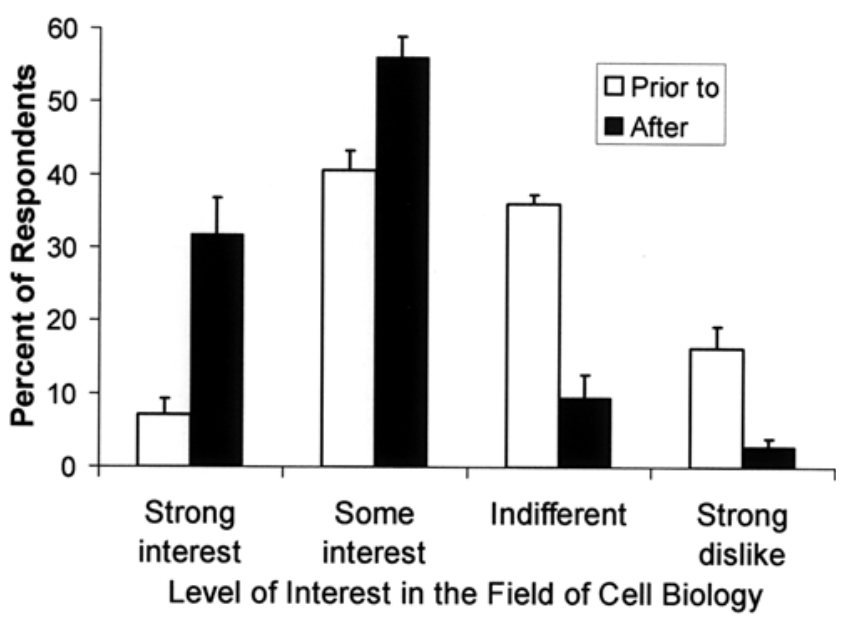

Figure 5. Students report increased interest in cell biology after completing course. In an end-of-the-semester assessment, students were asked to indicate their interest in the field of cell biology both prior to and after completing the course. Students were asked to select one of four descriptions: strong interest, some interest, indifferent, or strong dislike. The results are reported as mean percentage \pm s.e.m. for four semesters. Overall, there is a significant shift toward increased interest in cell biology after completion of the course $(p<0.0005$, Pearson chi-square). Prior to taking the course, only $7.2 \% \pm 2.2 \%$ of students reported having strong interest, and another $40.6 \% \pm 2.6 \%$ reported some interest. Students reported increases in both of these categories after taking the course, with values of $31.8 \% \pm 5.0 \%$ and $56.0 \% \pm 2.8 \%$, respectively. The percentage of students who indicated indifference to cell biology dropped from $36.0 \% \pm 1.3 \%$ to $9.4 \% \pm 3.2 \%$ after course completion, and only $2.8 \% \pm 1.1 \%$ still had a strong dislike for the field after the course, compared with $16.3 \% \pm 3.0 \%$ before the course.

and fruitful for students, inspiring them to enroll in subsequent courses related to cell biology, augmenting the numbers who choose cell biology-related careers, and encouraging lifelong learners of related topics.

In conclusion, we have redesigned a Cell Biology laboratory course that employs multiweek lab modules to establish an inquiry-based learning environment. This approach incorporates all of the important components of inquiry education, but allows us to work within the confines of large class size, modest budget, and limited access to lab space outside of scheduled class times. To determine whether the student learning experience was consistent with our goals at the outset of this project, we generated a quantitative assessment based on student comments about the lab. Initial data suggest that we have achieved many of our goals, and that students are enjoying lab more and developing critical thinking skills using the inquiry format. The multiweek lab module format appears to be an effective method to involve students in large cell biology courses in inquiry.

\section{REFERENCES}

Arce, J., and Betancourt, R. (1997). Student-designed experiments in scientific lab instruction: students at the University of Puerto Rico go back to the basics to learn chemistry concepts. J. Coll. Sci Teach. 27(2), 114-118.

Boyer Commission on Educating Undergraduates in the Research University (1998). Reinventing Undergraduate Education: A Blue- 
print for America's Research Universities. Stony Brook, NY: University of New York.

Bransford, J.D., Brown, A.L., and Cocking, R.R. (1999). How People Learn: Brain, Mind, Experience, and School. Washington DC: National Academy Press.

Brown, J. (1992) Theory or practice: what exactly is feminist pedagogy? J. Gen. Educ. 41, 51-63.

Crandall, G.D. (1997). Old wine into new bottles: how traditional lab exercises can be converted into investigative ones. J. Coll. Sci Teach. 26(6), 413-418.

D'Avanzo, C., and McNeal, A. (1997). Research for all students: structuring investigation into first-year courses. In: Student-Active Science: Models of Innovation in College Science Teaching, ed. A.P. McNeal and C. D'Avanzo. Philadelphia: Saunders College Publishing, 279-300.

Educational Testing Service (2005). Major field test in biology. http:// www.ets.org/hea/mft/discipline.html (accessed 24 March 2005).

Herreid, C.F. (1997). What makes a good case? The case study. J. Coll. Sci Teach. 27, 163-165.

Lemmers, C., Medina, E., Delgrossi, M.H., Michel, D., Arsanto, J.P., and Le Bivic, A. (2002). hINADl/PATJ, a homolog of discs lost, interacts with crumbs and localizes to tight junctions in human epithelial cells. J. Biol. Chem. 277, 25408-25415.

Middlecamp, C.H., and Subramaniam, B. (1999) What is feminist pedagogy? Useful ideas for teaching chemistry. J. Chem. Educ. 76, $520-525$.
National Research Council (1996). National Science Education Standards. Washington, DC: National Academies Press.

National Research Council (2000). Inquiry and the National Science Education Standards: A Guide for Teaching and Learning. Washington, DC: National Academies Press.

National Science Foundation (1996). Shaping the Future: New Expectations for Undergraduate Education in Science, Mathematics, Engineering, and Technology. Report on Review of Undergraduate Education. Arlington, VA: National Science Foundation, Directorate for Education and Human Resources.

Oliver-Hoyo, M., Allen, D., and Anderson, M. (2004). Inquiryguided instruction: practical issues of implementation. J. Coll. Sci Teach. 33(6), 20-24.

Sundberg, M.D. (1997). Assessing the effectiveness of an investigative laboratory to confront common misconceptions in life sciences. In: Student-Active Science: Models of Innovation in College Science Teaching, eds. A.P. McNeal and C. D'Avanzo. Philadelphia: Saunders College Publishing, 141-162.

Sundberg, M.S., Armstrong, J.E., Dini, M.L., and Wischusen, E.W. (2000). Some practical tips for instituting investigative biology laboratories. J. Coll. Sci Teach. 29(5), 353-359.

Tanner, K., and Allen, D. (2004). Approaches to biology teaching and learning: from assays to assessments-on collective evidence in science teaching. Cell Biol. Educ. 3, 69-74. 